\title{
Rehabilitation of the Hillendale Mine's residue storage facility
}

\author{
JA Beukes Tronox KZN Sands (Pty) Ltd, South Africa \\ ML Vlok Tronox KZN Sands (Pty) Ltd, South Africa \\ FE Khosa Tronox KZN Sands (Pty) Ltd, South Africa
}

\begin{abstract}
The Tronox KZN Sands Hillendale Mine is located in Zululand - close to Richards Bay. Mining activities commenced in 2001 and the mine's production came to an end in 2013. At Hillendale, dunes with a high fines content were mined to recover the valuable minerals of ilmenite Zircon and rutile. The fine fraction consisting mainly of fine clay minerals was managed by storage in a residue storage facility (RSF). Following the cessation of mining activities several actions have been implemented towards achieving mine closure. This paper will firstly give some basic background on the operation of the residue facility as part of the Hillendale Mine. Secondly the paper will focus on mine closure activities planned and implemented at the RSF. The learnings and experience gained from the Hillendale Mine will form the basis of future closure plans for RSFs operated as part of Tronox's newly established mine at Fairbreeze.
\end{abstract}

Keywords: rehabilitation, residue storage facility, mine closure

\section{Introduction}

Tronox is a vertically integrated pigment producer with a global footprint. Its KZN Sands operation consists of a mine in the closure phase at Hillendale as well as the current operating Fairbreeze Mine. The mining operation produces feed for the Central Processing Complex (CPC) in Empangeni where the concentrate is further processed to final products of rutile, zircon, high titania slag and pig iron.

The Hillendale Mine is located close to Richards Bay, adjacent to the town of Esikhaweni. The orebody, consisting of ancient red sand dunes, was removed to depths of up to $65 \mathrm{~m}$ by hydraulic mining. The ore was beneficiated in a gravity separation circuit to produce a heavy mineral concentrate (HMC), with sand tailings being returned to reconstruct the mined dunes and the majority of the fines fraction disposed in a residue storage facility (RSF). The RSF was constructed with starter walls of compacted soil. Coarse sand tailings were then used to lift the walls further as illustrated by Figure 1. The fines residue was deposited through a pipeline system around the RSF. Mining operations commenced in 2001 and were completed in 2013.

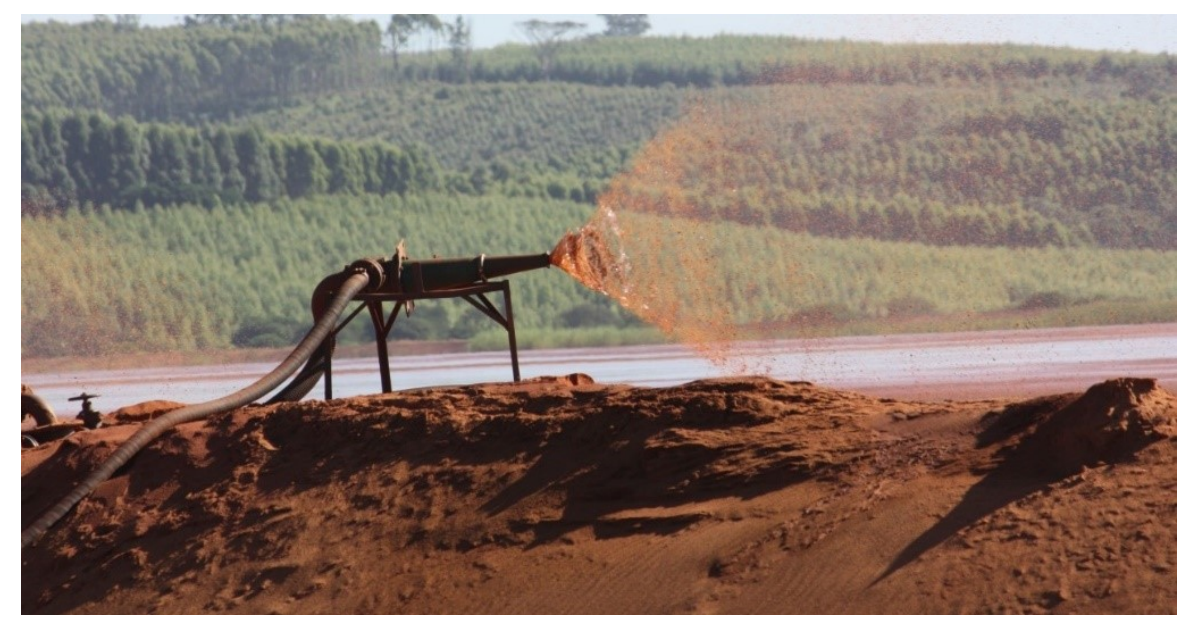

Figure 1 Residue storage facility wall raising using coarse tailings pumped from the process plant 
The Hillendale Mine is currently in the rehabilitation phase with the aim of applying for mine closure. The rehabilitation of the RSF is one of the key focus areas and would be critical in achieving successful mine closure. In this paper the rehabilitation of this facility will be reviewed, both completed and current activities will be presented. As KZN Sands are operating a similar RSF at its current Fairbreeze Mine the learnings from the Hillendale RSF rehabilitation will be invaluable in optimising closure plans for the Fairbreeze RSF.

\section{Hillendale residue storage facility operational review}

The Hillendale RSF footprint covers an area measuring 130 ha. It lies in the alluvial floodplain of the Mhlatuze River, at an average altitude of approximately $15 \mathrm{~m}$ above mean sea level (mamsl). The general geology of the area is represented by gneissic rocks of the natal structural and metamorphic Province; Cretaceous St. Lucia formation and Quaternary deposits of the Berea Formation as well as unconsolidated estuarine and alluvial deposits. The RSF was commissioned in 2001 for -45 micron size fine tailings slurry disposal.

The footprint of the residue perimeter wall was founded on sandy sub-surface material with relatively high strength properties. The outer and inner wall was designed according to the slope of $1 \mathrm{~V}: 3 \mathrm{H}$ and $1 \mathrm{~V}: 2 \mathrm{H}$ respectively.

Figure 2 shows the operational features imposed on an aerial photograph of the RSF taken during the rehabilitation phase.

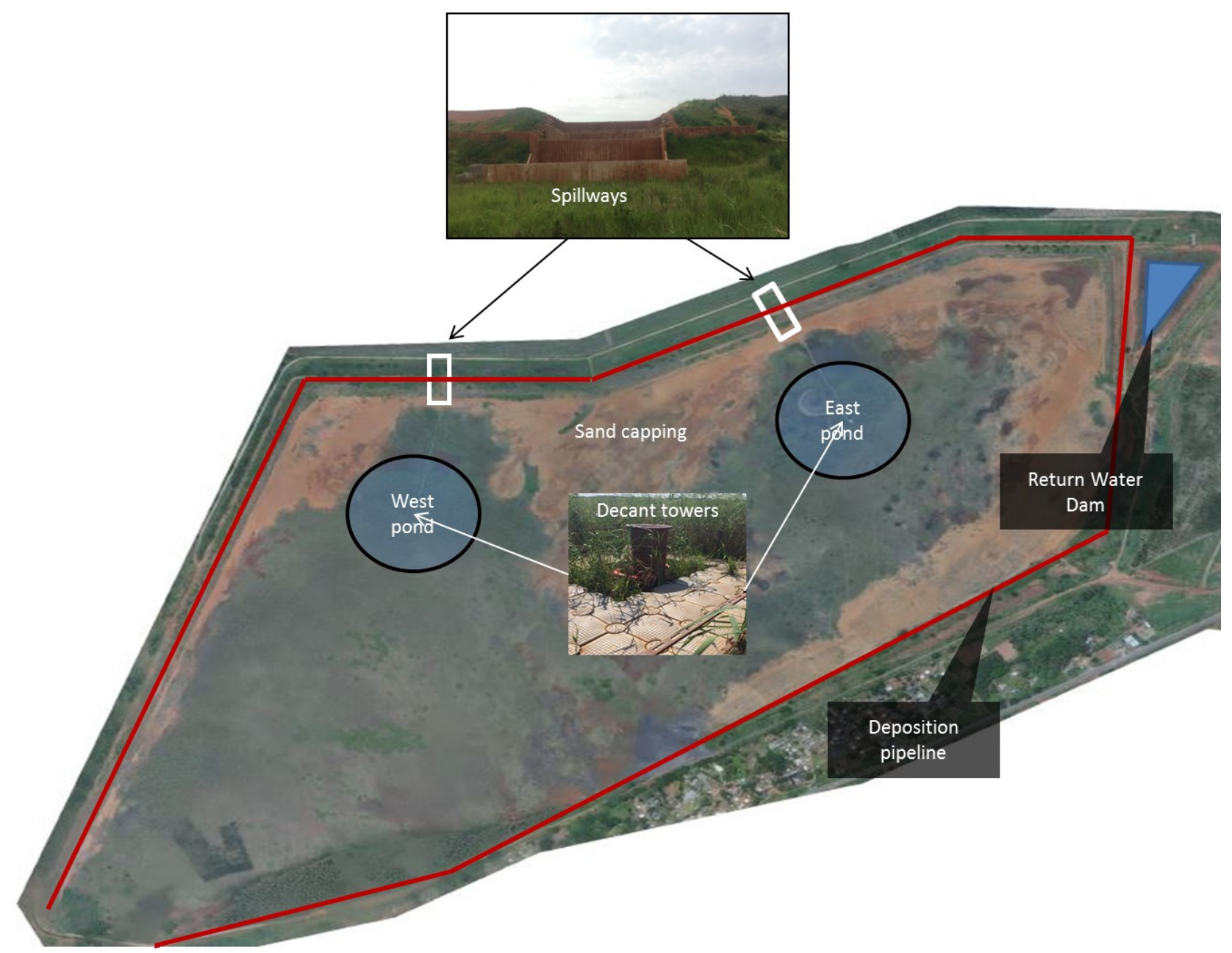

Figure 2 Residue storage facility operational features 
The design principle for disposal of the -45 micron size residue slurry is to place it in layers of controlled thickness on a rotational cycle that ensures a controlled optimum drying time for each layer before the next layer is added. The rotational deposition was made possible by having a delivery pipeline around the facility as indicated in Figure 2. The relationship between layer thickness and drying cycle for a given residue disposal tonnage and concentration is determined by the disposal rate, evaporation rate, rainfall and availability of the surface area for residue disposal.

The water decant system consists of a gravity emergency system and a pumped duty system on both east and west decant. The decant tower positions are also indicated in Figure 2. The $600 \mathrm{~mm}$ diameter decant tower together with the barge pump system was designed to decant the rain water and supernatant water at a rate of $0.7 \mathrm{~m}^{3} / \mathrm{s}$, i.e. combined west and east flow capacity of $1.4 \mathrm{~m}^{3} / \mathrm{s}$.

Table 1 contains information regarding the key RSF parameters and shows how the production scenario deviated from the original design.

Table 1 Comparison between design and operational parameters for the Hillendale residue storage facility

\begin{tabular}{lcc}
\hline & Original design parameters & Operational parameters \\
\hline Disposal tonnage per month & $137,500 \mathrm{tpm}$ & $137,500 \mathrm{tpm}$ \\
Residue slurry density & $1.21 \mathrm{t} / \mathrm{m}^{3}$ & $1.2 \mathrm{t} / \mathrm{m}^{3}$ \\
Max sand content in residue slurry & $10 \%$ & $6.2 \%$ \\
Operational life & $6.75 \mathrm{yrs}$ & $>10 \mathrm{yrs}$ \\
Tonnage to be stored & $11,137,500 \mathrm{t}$ & $>16,500,000 \mathrm{t}$ \\
Rate of rise & $1.12 \mathrm{~m} / \mathrm{a}$ & $1.36 \mathrm{~m} / \mathrm{a}$ \\
In situ residue dry density & $1.2 \mathrm{t} / \mathrm{m}^{3}$ & $0.88 \mathrm{t} / \mathrm{m}^{3}$ \\
Derived final top elevation of the deposit & $+21 \mathrm{mamsl}(9 \mathrm{~m}$ high) & $+26.5 \mathrm{mamsl}(14.5 \mathrm{~m}$ high) \\
\hline
\end{tabular}

The lower in situ dry density of the residue when compared to the design target (Table 1) have significantly increased the annual rate of rise. Additional mining areas also extended the design life and total tonnage stored. These operational factors have had a negative impact by increasing the final RSF elevation when compared to the original design.

\section{$3 \quad$ Mine closure process}

Under South African mining legislation, once a mine reaches the end of its operational life, it needs to embark on a closure process. This process, apart from the rehabilitation that needs to be affected, also governs the administrative steps to allow the government to review the remaining risks and reach a point where the mining licence can be cancelled.

Tronox KZN Sands has initiated the closure process for the Hillendale Mine operations as per the Mineral and Petroleum Resources Development Act, 2002 (Act No. 28 of 2002) (Republic of South Africa 2002). The mine ceased production activities at the end of 2013 and, over the past years, activities onsite were towards achieving mine closure inclusive of the RSF. 
Tronox KZN Sands' key aims for the mine rehabilitation are listed here. Each key aim was supported by a suite of key objectives aligned to the mine closure process:

- Safe and healthy post-mining environment.

- Economically viable and sustainable post-mining land use.

- Limited residual environmental impact.

- Optimal post-mining social opportunities.

By achieving the key aims Tronox KZN Sands' Hillendale Mine will be able to apply for closure on the four different mining rights which cover the operation known as the Hillendale Mine.

\section{$4 \quad$ Residue storage facility rehabilitation planning phase}

As part of the preparation for mine closure a 'mine closure plan and risk report' was developed. This report followed a risk-based approach for the full mining area at Hillendale. The rehabilitation planning was thus focused on managing the identified risks. As part of the mining right area, specific plans were also developed for the RSF. These plans included shaping the top surface to drain to three future spillways situated in the vicinity of the eastern walkway, the western walkway and the southwestern corner of the RSF (only two were eventually built). This was planned to be achieved through a selective deposition strategy aimed for completion by June 2011. From July 2011, the plan was to mix sand and fines together to generate a sand:fines mix for pumping to the RSF in situ fines surface and to stockpile sufficient material to cover the RSF with a $1.5 \mathrm{~m}$ thick layer of sand:fines mix. Once the facility was capped, the plan was to then remove all piping infrastructure. For the Hillendale Mine RSF the planned post-mining land use was sugarcane cultivation and the final stage of the rehabilitation plan was to establish the crop on the RSF. Due to the limited capacity of the plant constructed to produce the sand and fines mixture the intended plan of covering the RSF with this material was not possible. As an alternative it was decided to cover the facility with only coarse sand to around $1 \mathrm{~m}$ in thickness. The main aim of the cover was to allow agricultural vehicles to access the top surface of the facility.

As the rehabilitation progresses, the mine closure and risk report is updated to reflect completed activities as well as remaining aspects that could still pose a risk requiring attention. As the closure process follows a risk-based approach, changes to the rehabilitation plan can be made if the implemented strategy is still effective in managing the identified risks and is in line with the overall closure objectives.

\section{$5 \quad$ Residue storage facility rehabilitation actions}

A brief description of the main rehabilitation activities will follow illustrating how alternative methods were identified during the implementation in cases where original plans were not adequate.

\subsection{Grassing of external walls}

The original starter wall was grassed during the construction phase. The wall was however continuously lifted through adding coarse sand as discussed and illustrated in Figure 1. Due to this continual process grassing of the sand wall could only be executed once the wall reached its final height. The outside of the perimeter wall of the RSF was planted with grass sods sourced from a local supplier. Grass is planted on the RSF walls to form an erosion barrier on the perimeter wall of the RSF. Figure 3 shows the grassing process. 


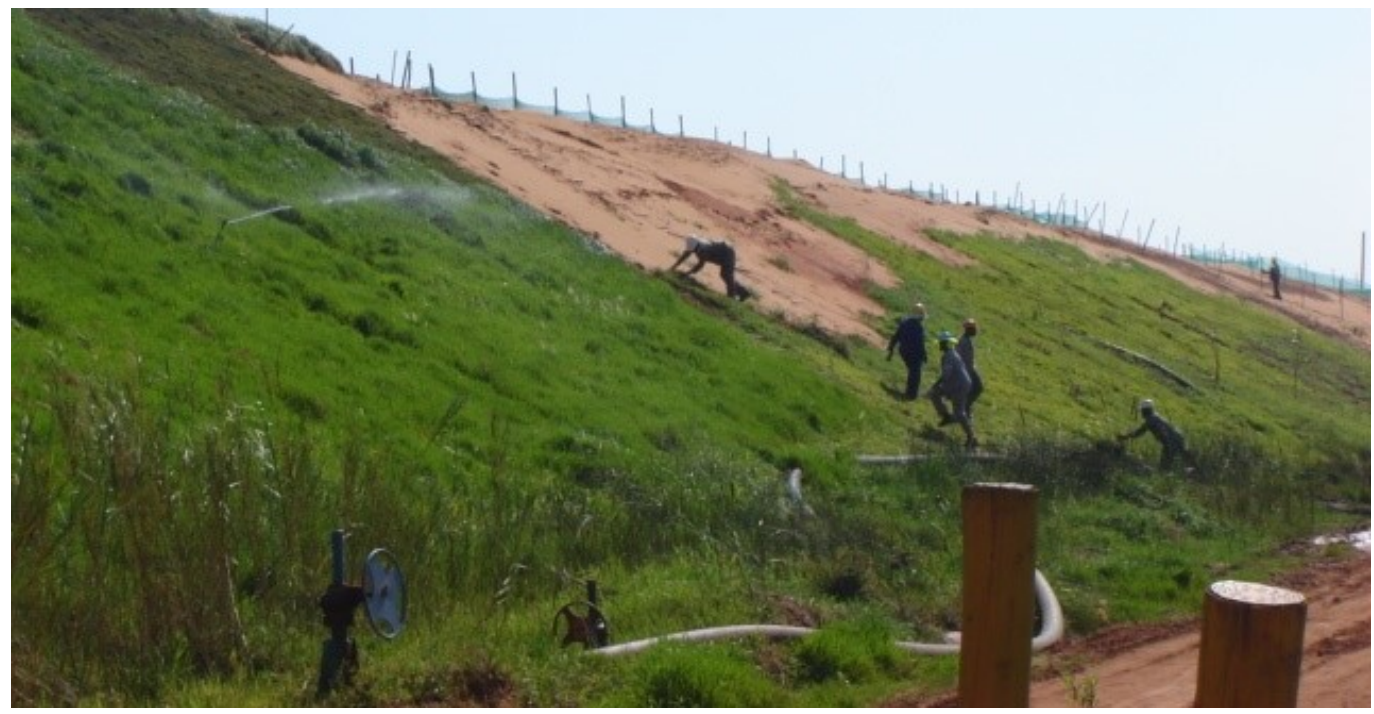

Figure 3 Placing of grass matting on the outside of the residue storage facility sand walls

\subsection{Relocation of the decant pools}

As the plan was for the RSF to drain freely through spillways constructed on its sand walls the operational surface contour needed to be amended. As previously described, during operation residue was discharged around the RSF perimeter in a cyclical fashion. The bleed and runoff water collected at two centrally located penstocks. To achieve a surface that would allow water to drain to the planned spillways, deposition was managed for the final two years of operation with only the southeastern deposition points used. That allowed for a slope to be established running from the southeast to the northwestern wall of the RSF, where the spillways were planned. Figures 4 and 5 show the planned contours as well as an aerial photograph taken during the selective deposition phase respectively.

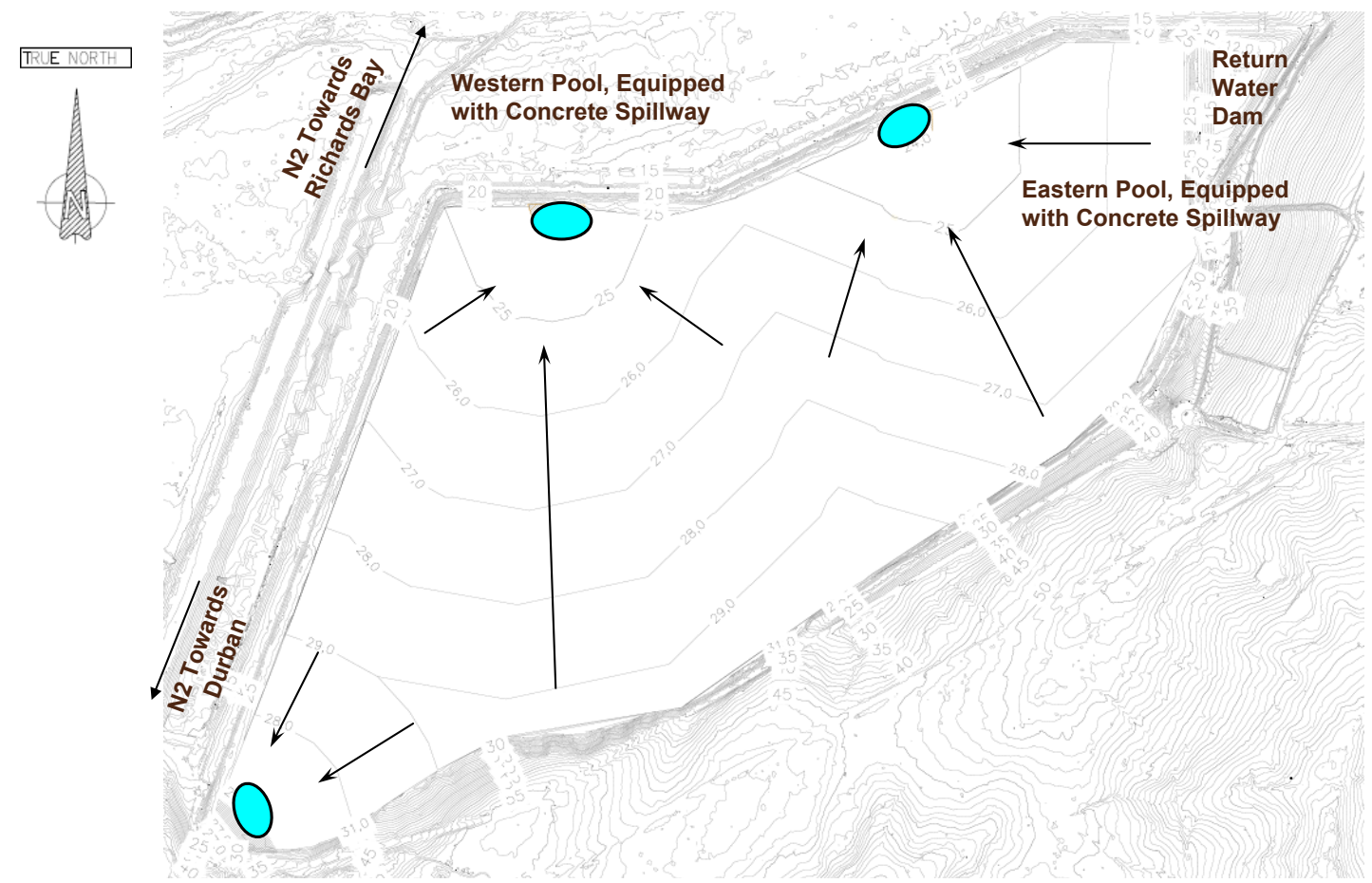

Figure 4 Concept design of the residue storage facility closure drainage pathways 


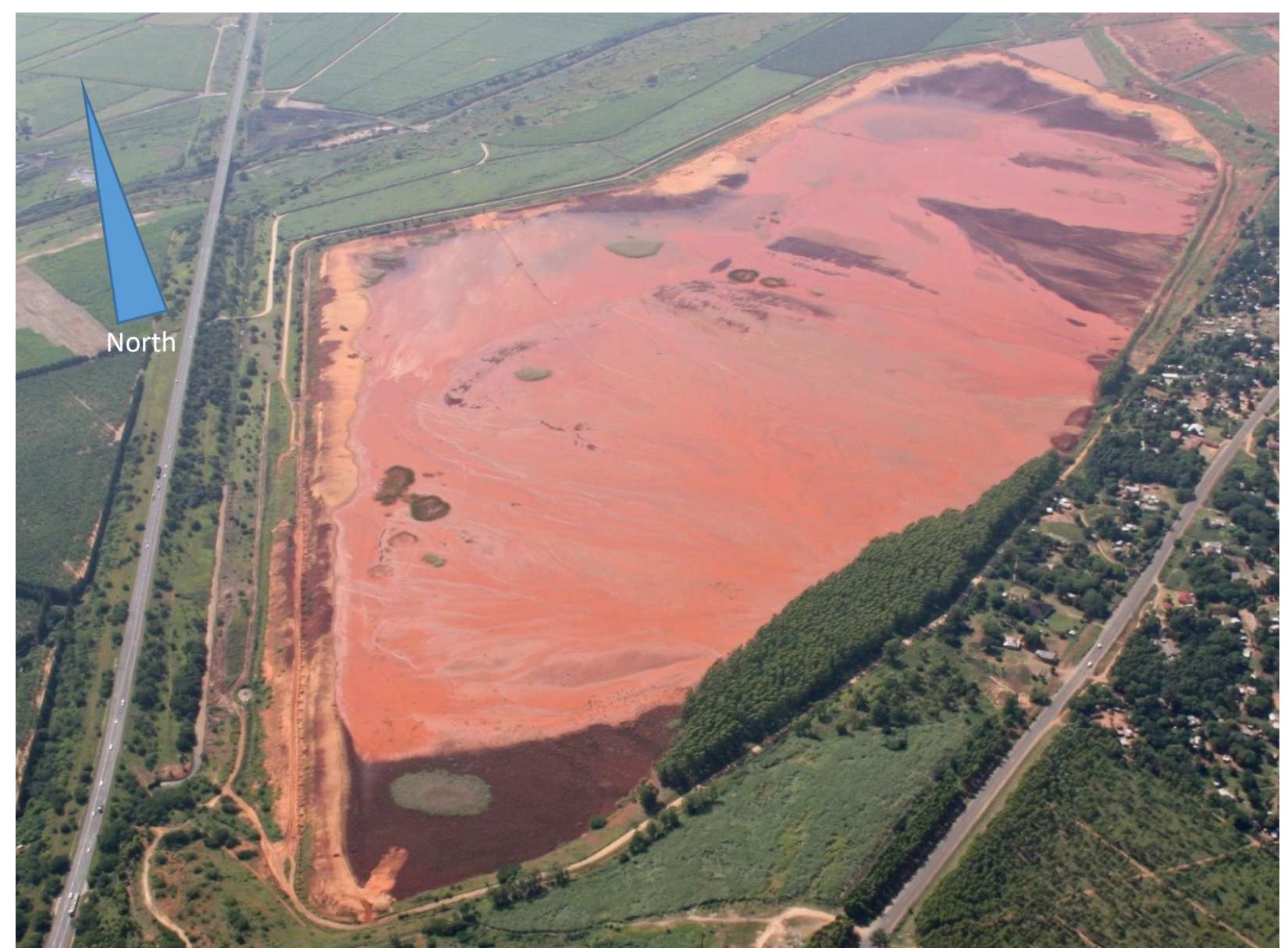

Figure 5 Aerial photograph showing the depositing of fines from the southeastern side of the residue storage facility

\subsection{Sand capping}

As one of the closure criteria for the Hillendale Mine is to have sustainable agriculture, one of the goals was to develop a trafficable surface on the RSF for typical farming equipment. The residue material deposited following the cessation of operations formed a crust of dried clay but in the process isolated the underlying wet residue from further significant drying. The permeability of the wet residue is also very low requiring some form of intervention to achieve the goal of a trafficable surface. The first attempt to achieve this goal was to cap the facility with a sand layer of 1-1.5 m thick. The capping, if slowly applied and evenly spread, would assist by distributing any point load to such a degree that access would be safe. This strategy had mixed success. Initially, while the mining operation was still in progress, sections of the facility could be capped at a good rate. Once mining ceased however, the hydraulic transport of sand to the facility became ineffective due to low sand densities and was suspended.

Around 30 hectares of the site was capped with sand and some sugar cane was successfully established on the material. Good moisture retention was achieved in the sand due to the impermeable layer at around $1 \mathrm{~m}$ depth. The sections capped could support traffic and travel routes could be established. Figures 6 to 8 show the deposition process, area covered and an aerial view of the RSF following the capping and sugar cane establishment on selected sections. 


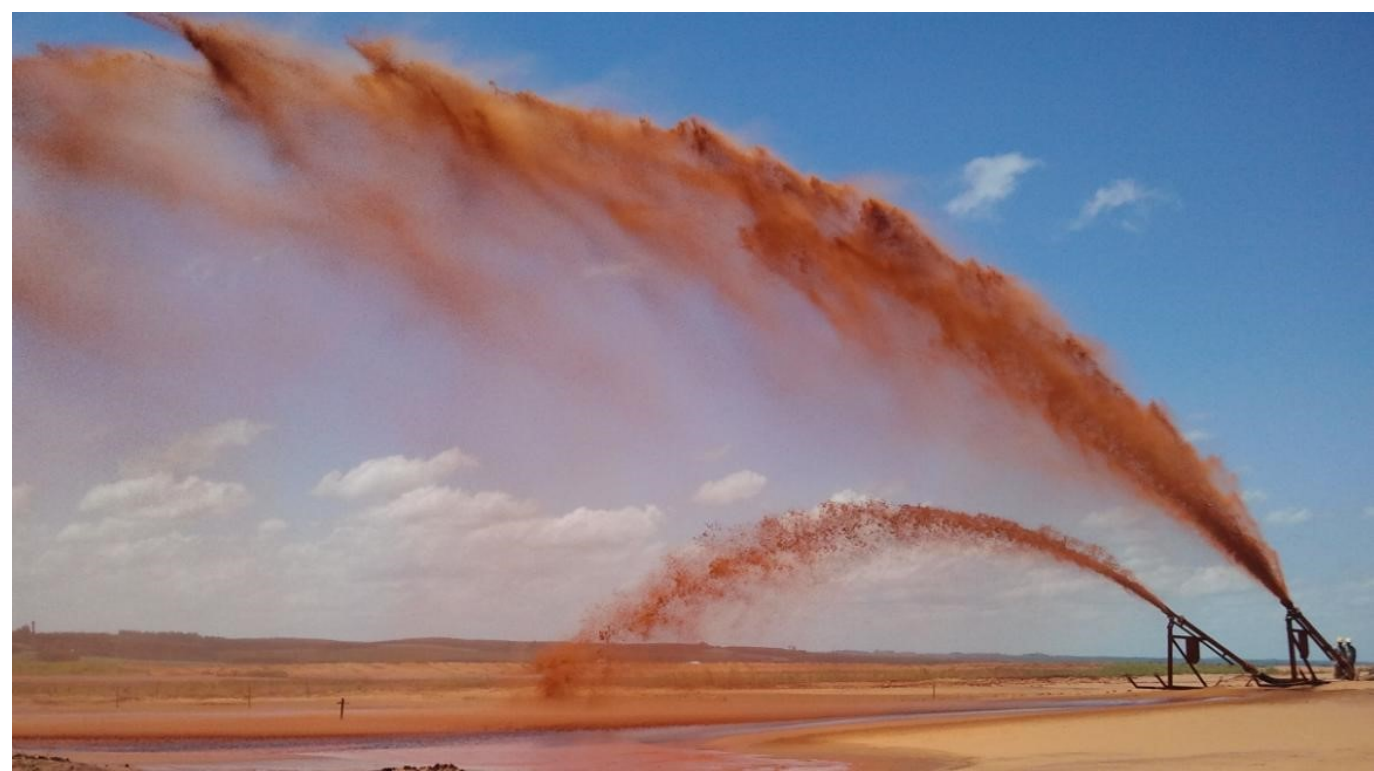

Figure 6 Coarse sand sprayed onto the residue storage facility surface in the capping process

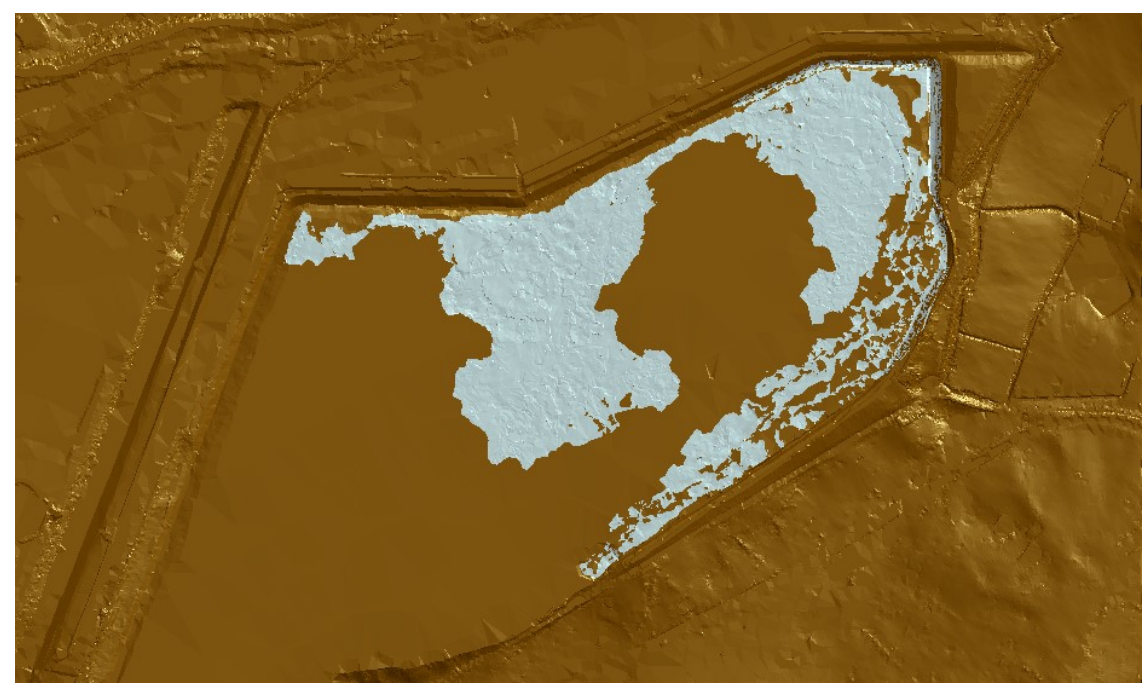

Figure 7 Survey of the areas capped with coarse sand

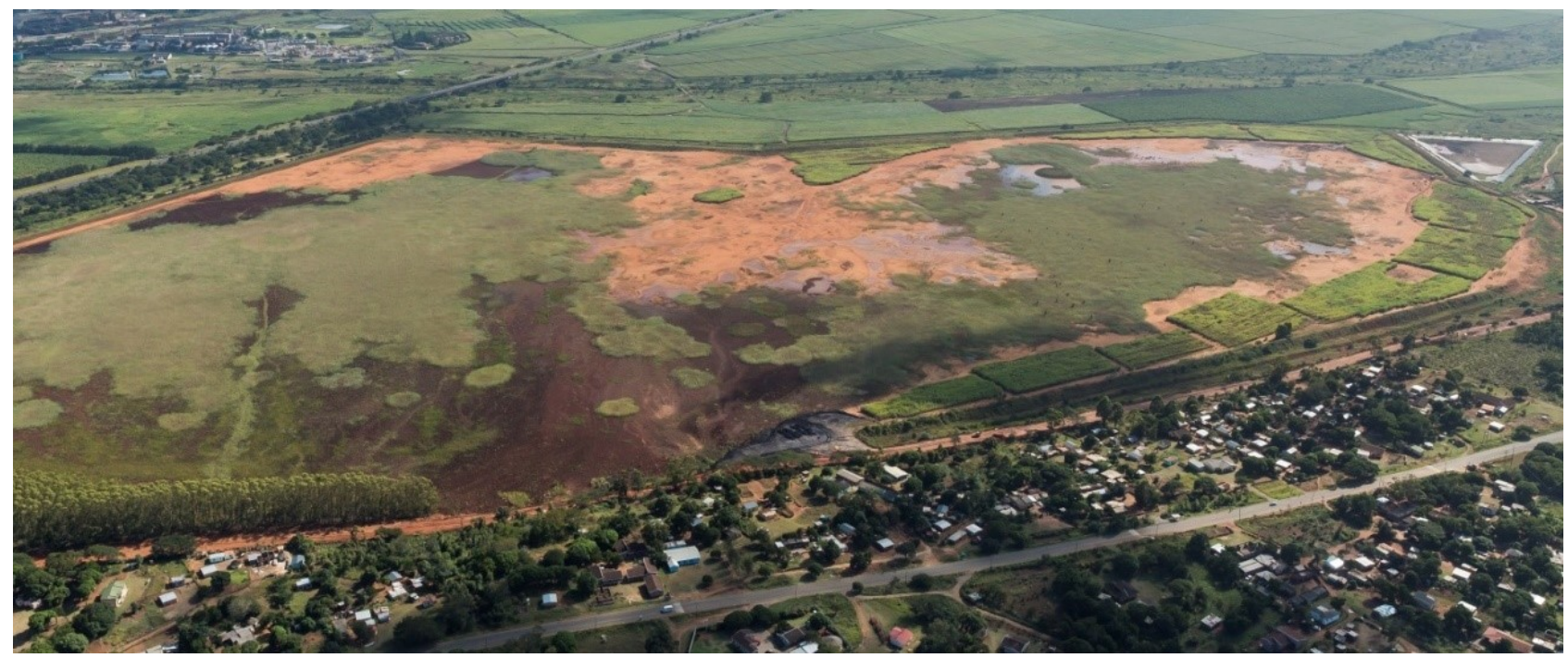

Figure 8 Aerial view of the residue storage facility where the areas capped with sand are visible 


\subsection{Eucalyptus trees}

As discussed, some initial attempts were made to deposit coarse material over the RSF to create a stable surface layer. This dumping has had localised effects and has allowed access to plant sugar cane in sections along the northeastern and southeastern periphery of the RSF. Trials were subsequently initiated to promote desiccation through the establishment of casuarina and eucalyptus trees. These trials, located in the southwestern portion of the RSF have served to dramatically increase surface desiccation, resulting in large cracks forming under these tree stands. These cracks appear to slowly fill in naturally over time and therefore appear to be a solution to dewatering the fine residue deposited in the RSF. This has led to the expansion of planting programs, with eucalyptus seedlings now planted in the drier sections of the RSF.

The tree stabilisation was monitored by a forestry consultant who confirmed acceptable performance of trees on the RSF. The plan is to expand the establishment of trees to the majority of the RSF surface to assist in reducing the retained moisture/water levels in the upper layers to provide the required stability. Factors to be monitored are the impact if rainfall returns to typical levels and if dewatered layers re-absorb significant quantities of water or if structures are maintained.

Figures 9 and 10 show the trial establishment and crack development in the fines.

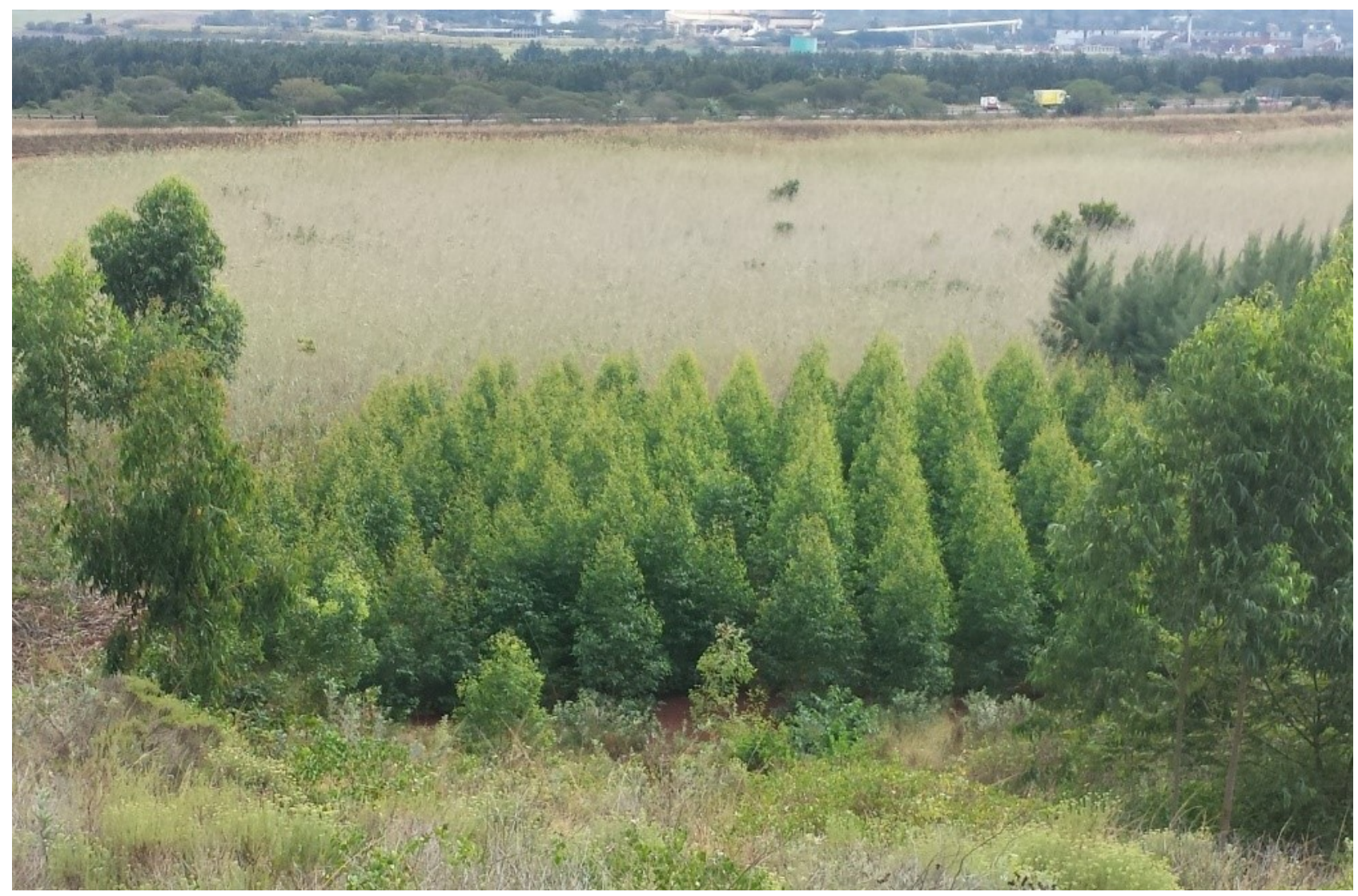

Figure 9 Trial area with eucalyptus trees 


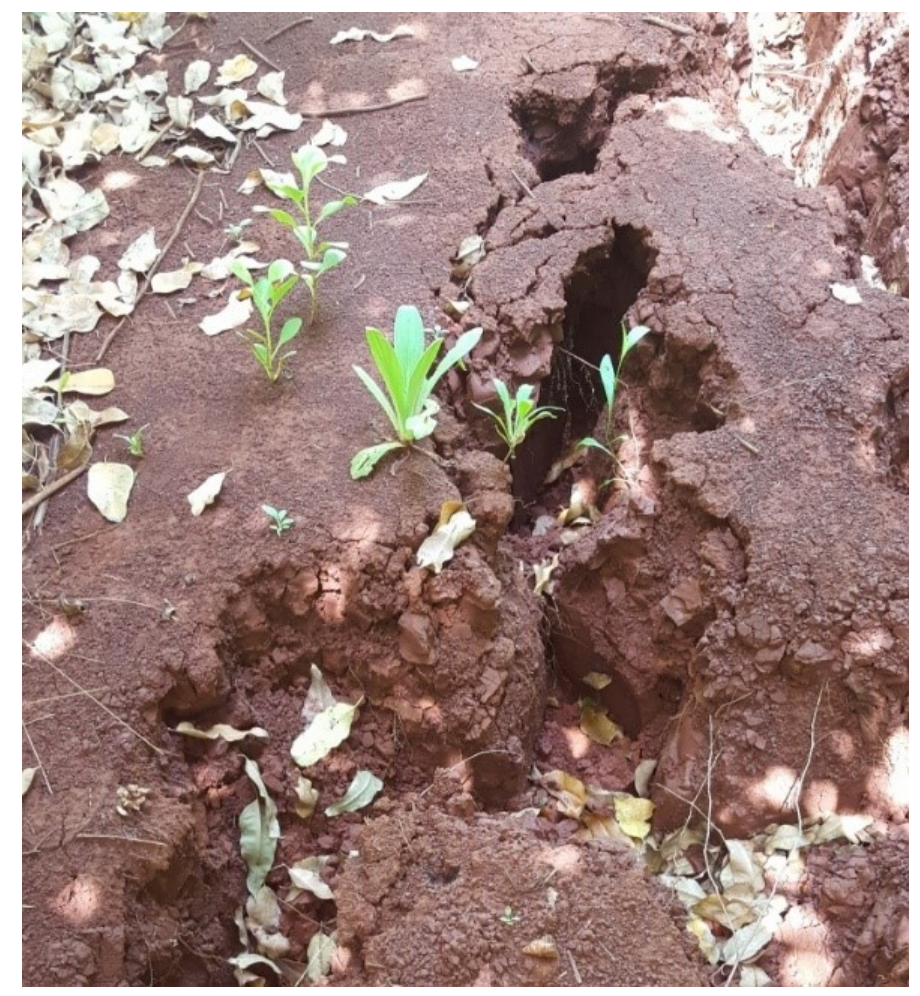

Figure 10 Effect of moisture reduction in the fines in the eucalyptus trial block on the residue storage facility

\subsection{Spillway construction}

During the operational life the RSF was drained through two penstocks. As these facilities would require maintenance in the long-term, an alternative safe drainage pathway was established for the RSF. Two spillways were constructed to allow safe water discharge over the sand wall of the RSF. The design consisted of concreted steps with Armor flex protection and lined flow sections between the steps. Figure 11 shows a side view of the basic design while the final constructed facility is shown in Figure 12.

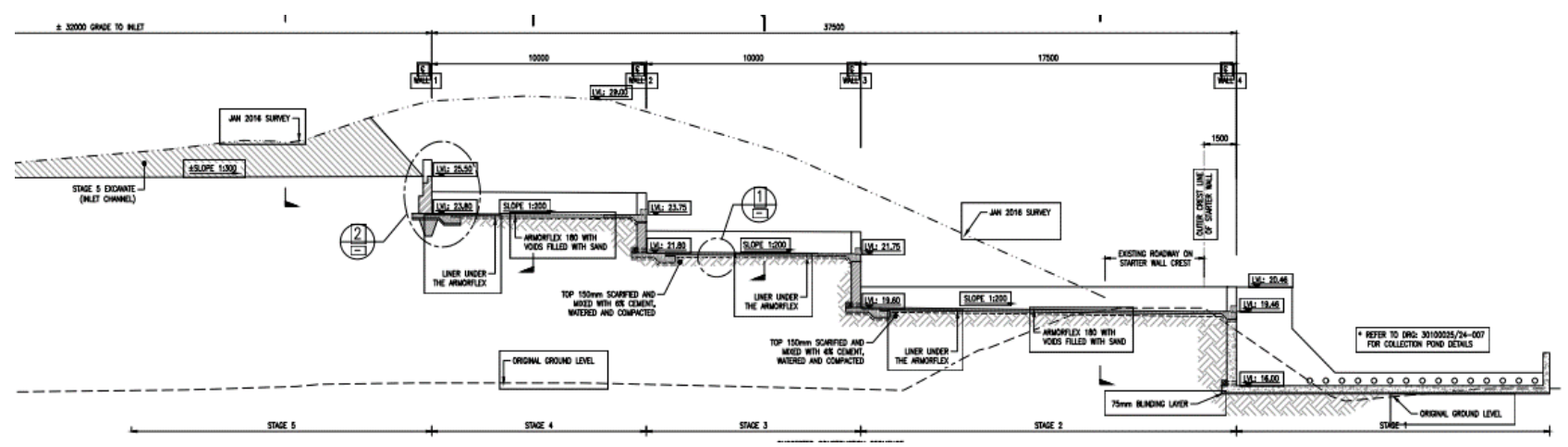

Figure 11 Side view of the spillway design to take water from the top of the fines level to the outside of the starter wall position through several drops

One of the lessons learned from the spillway construction is that the levels of the residue reduced over time. The fine residue settled in the RSF and as a result there was an elevation difference of approximately $1 \mathrm{~m}$ between the design level and the level at completion of the construction. Provision was made for future reduced surface levels; however, this could have been more since the fine material has settled significantly more than predicted.

During a very large storm event a water pool will thus form before the facility will overflow. 


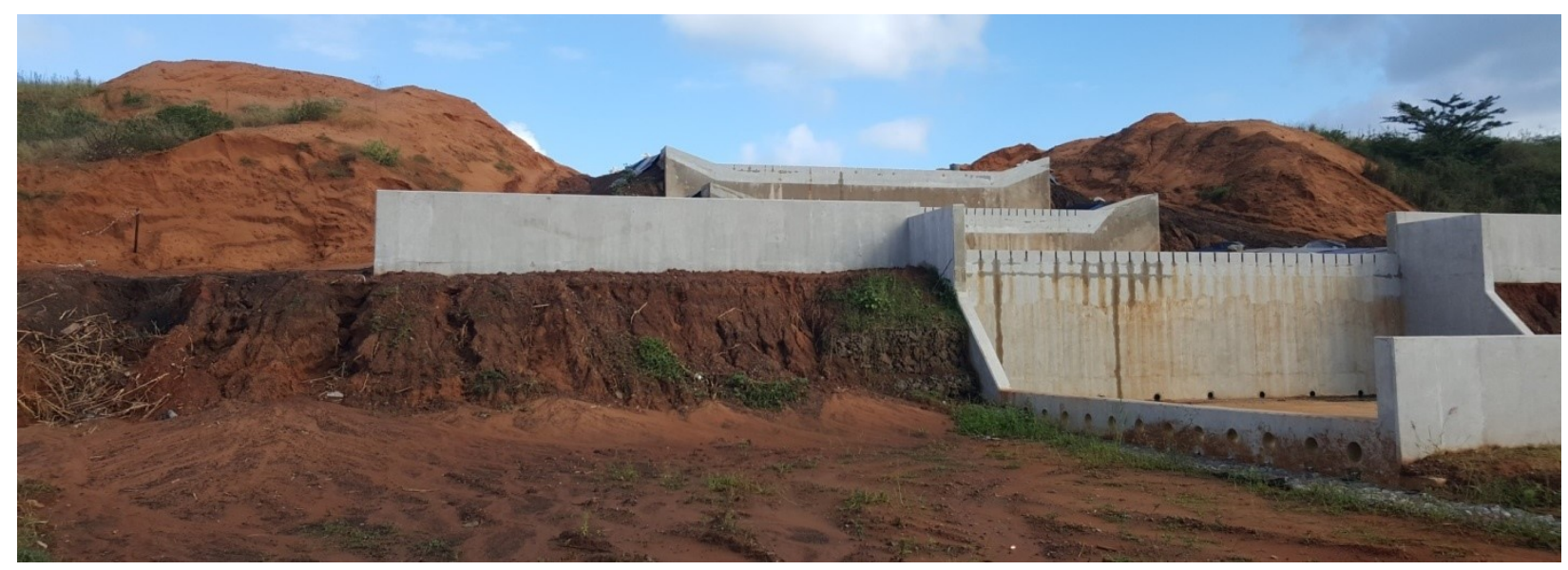

Figure 12 Completed concrete spillway showing the consecutive drops and release on the natural ground level outside the wall footprint

\subsection{Ecological assessment}

In the case of the Hillendale RSF, wetland vegetation initially became established in response to the high availability of water associated with the fine residue material. Initial establishment of vegetation is evident in aerial photography from as early as 2004 when active pumping of fines into the area was underway. Pockets of vegetation continued to take root as operations continued with rapid colonisation taking place from 2012 as mining operations began coming to an end. Since residue inputs ceased, efforts have intensified to promote the desiccation of fines by managing surface water. This was achieved by evaporation of water from pooled surface water around the penstock and low points; and systematically lowering the inflow elevation of the two penstocks to which the water gravitates, this is then piped directly into the nearby Mhlathuze River. Transpiration by plants adds to this effect, thereby helping to promote desiccation. Whilst transpiration losses from wetland vegetation contributes to water losses, it is unclear from scientific research whether or not wetland vegetation enhances water loss relative to what would occur from open water.

A dense cover of wetland vegetation now occurs across most of the RSF. Vegetation communities were mapped. Phragmites australis is clearly the best adapted to the conditions and is dominant over much of the RSF. This includes areas that are regularly inundated around the penstocks as well as less saturated areas towards the periphery of the site. Typha capensis is another common species although it appears to be outcompeted by Phragmites under most circumstances. A small area is dominated by Andropogan eucomus, another obligate wetland species. Whilst diversity of plant species is generally low, depressions add diversity to the habitat and 21 plant species were recorded.

For wetland vegetation to persist in the long-term, soil moisture must remain high within the rooting zone of established wetland plants. While good vegetation growth is evident on the RSF, deepening of the dry surface layers is likely to induce stress and die-off of obligate wetland plants over time. Whilst these plants may be replaced by facultative wetland plants initially, wetland vegetation is likely to be replaced by terrestrial species over the longer term as surface layers desiccate further.

The areas around the penstocks would remain as depressions and would be the zone where water accumulates. It is thus foreseen that even though the current widespread of wetland vegetation may reduce and be replaced over time that some areas may remain and develop in wetlands in the long-term. These will be monitored in terms of natural succession and increased diversity over time. Figure 13 shows large areas of Phragmites reeds. 


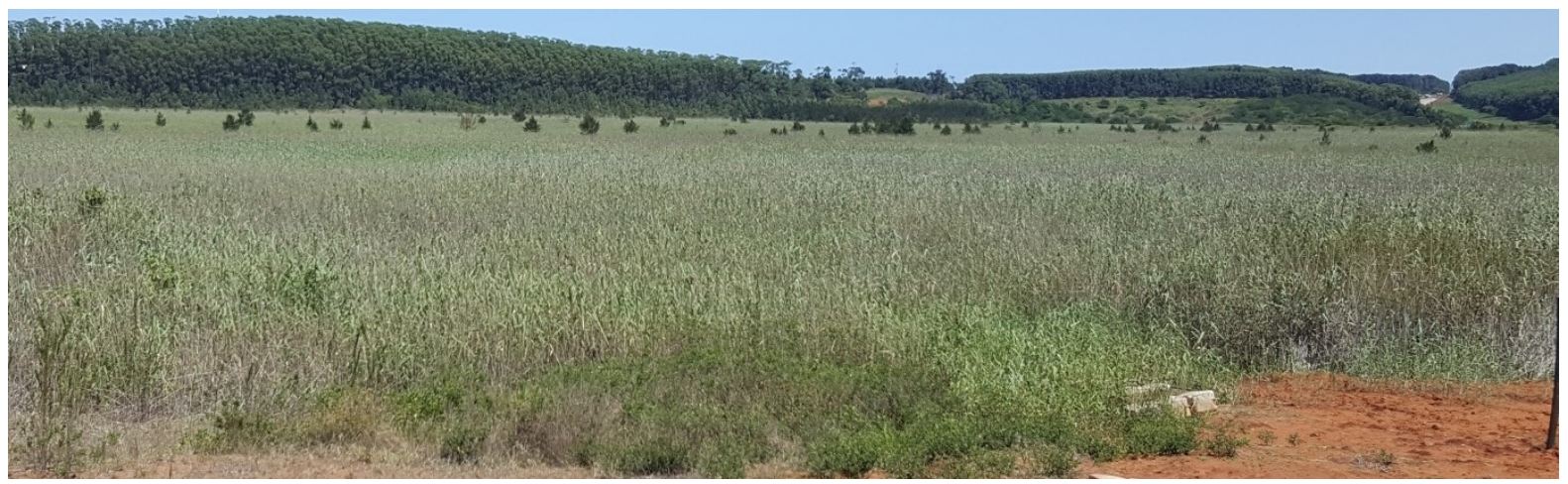

Figure 13 Significant areas with established reeds

\section{Outstanding activities and closure application}

To complete the rehabilitation activities on the RSF and get the facility to a state where a closure application would have a reasonable chance of succeeding some more activities need to be completed. Firstly, the strategy to use eucalyptus trees to stabilise the upper layer of the facility needs to be completed. Several trees have been established as discussed in section 5.4 but expanding the planting and time is required for the effect to take place and the success to be determined. Once the trees have managed to reduce the moisture content of the upper layers of the facility the ability of the material to accommodate vehicle traffic would need to be tested and safe areas defined on the facility. Due to certain areas expected to remain as pools and thus wetlands, the full facility will not be accessible. The penstocks which served the facility during operation would need to be made safe by blocking it as not to form a pathway for fines to escape. This is planned for after the stability of the top layer could be confirmed. While these activities may still take some time, care and maintenance will be an ongoing effort. Aftercare and maintenance has already commenced during the operational phase of the mine, on areas that were rehabilitated during the active mining period. Aftercare and maintenance includes:

- Erosion control and management.

- Maintenance of infrastructure.

- Geotechnical and RSF safety work.

- Control and eradication of alien weeds.

- Monitoring of:

- Surface and groundwater quality.

- Vegetation.

- Eucalyptus areas.

Once the mine rehabilitation reaches a state where a formal closure application can be submitted, typical steps that will be required includes:

- Stakeholder engagement with the Department of Mineral Resource (DMR), surrounding communities, other interested and affected parties, other relevant authorities and previous land owners.

- Updating of the closure plan and risk report to reflect the completed rehabilitation and any remaining risks and management measures required into the future.

- Specialist studies to inform the success of rehabilitation measures in achieving closure objectives, these will typically be environmental and safety-based assessments.

- Compilation of statutory application documents.

- Finally, inspections and audits by the authorities. 


\section{Conclusion}

The Hillendale RSF rehabilitation process is ongoing even though most of the activities have been completed. The remaining process would require some time as the growth of the planted trees is expected to modify the fines water content as it matures and increases coverage. Parallel to the expansion of trees on the facility the regulatory process leading to a closure application will be pursued.

From the rehabilitation efforts of the RSF at Hillendale several learnings can be included in planning for the Fairbreeze Mine which has a similar facility. Arrangements and establishment of trees on the facility as soon as possible following the end of operation will be more efficient. This is attributed due to wetland vegetation which establishes quite quickly following cessation of fines deposition, and once established, provides competition to young seedlings. A further learning would be to give the facility more time to settle prior to designing and constructing the final spillways.

\section{Acknowledgement}

We acknowledge Boela Bekker and his team for implementing the rehabilitation on the RSF and their innovative ideas.

\section{Reference}

Republic of South Africa 2002, Mineral and Petroleum Resources Development Act No. 28 of 2002, Government Gazette, vol. 448, no. 23922, 10 October 2002, Republic of South Africa. 